\title{
First Quarter Report of Electrical Resistivity Monitoring of the Drift Scale Test
}

A. Ramirez

W. Daily

June 1998

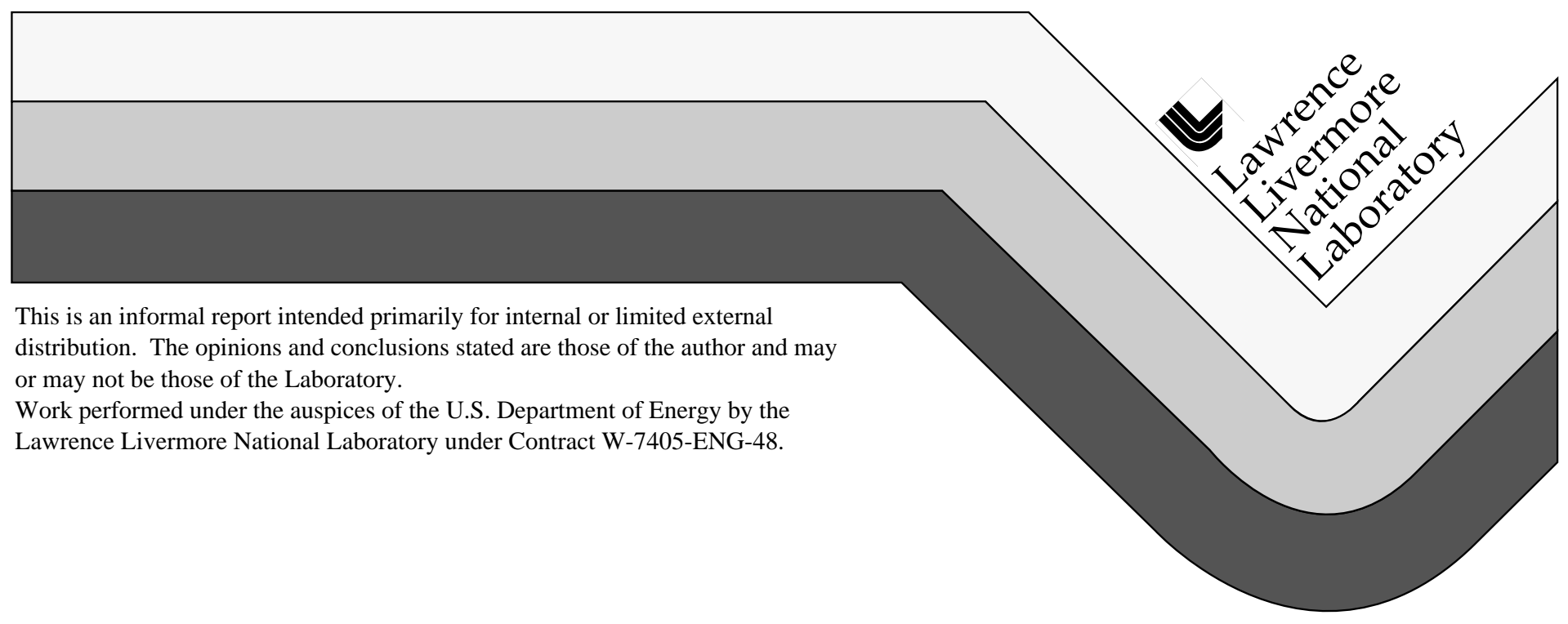




\section{DISCLAIMER}

This document was prepared as an account of work sponsored by an agency of the United States Government. Neither the United States Government nor the University of California nor any of their employees, makes any warranty, express or implied, or assumes any legal liability or responsibility for the accuracy, completeness, or usefulness of any information, apparatus, product, or process disclosed, or represents that its use would not infringe privately owned rights. Reference herein to any specific commercial product, process, or service by trade name, trademark, manufacturer, or otherwise, does not necessarily constitute or imply its endorsement, recommendation, or favoring by the United States Government or the University of California. The views and opinions of authors expressed herein do not necessarily state or reflect those of the United States Government or the University of California, and shall not be used for advertising or product endorsement purposes.

This report has been reproduced directly from the best available copy.

Available to DOE and DOE contractors from the Office of Scientific and Technical Information P.O. Box 62, Oak Ridge, TN 37831

Prices available from (423) 576-8401

Available to the public from the National Technical Information Service

U.S. Department of Commerce 5285 Port Royal Rd. Springfield, VA 22161 


\title{
Electrical Resistivity Monitoring of the Drift Scale Test in Yucca Mountain, 2nd Quarter FY98
}

\author{
A. Ramirez, W. Daily \\ Lawrence Livermore National Laboratory
}

\begin{abstract}
Electrical resistance tomography (ERT) is one of the several thermal, mechanical and hydrological measurements being used to monitor the rockmass response during the Drift Scale Test (DST). ERT is being used to monitor the behavior of liquid water with a special interest in the movement of condensate out of the system. Eight boreholes, containing a total of 140 ERT electrodes, were drilled above and below the Heated Drift (HD) to form vertical planes parallel to the drift. In addition, 4 boreholes, containing 60 electrodes, drilled from the Access Observation Drift (AOD)form vertical planes at right angles to the HD. Images of resistivity change were calculated using data collected before and during the heating episode. The changes recovered show two regions of decreasing resistivity, one approximately centered around the wing heaters, and a second one centered around the HD. These regions grow with time and the resistivity decreases become stronger. The changes in resistivity are caused by both temperature and saturation changes. The Waxman Smits model has been used to calculate rock saturations after accounting for temperature effects. The saturation estimates suggest that a relatively large region of drying develops around the wing heaters and grows over time; a second, smaller drying region is developing above the crown of the HD. The accuracy of the saturation estimates is limited due to a variety of factors discussed below.
\end{abstract}

\section{Introduction:}

The Drift Scale test (DST) is one of the in situ thermal tests being conducted in the exploratory studies facility (ESF) in Yucca Mountain to enhance the understanding of the coupled processes. The primary objective of the DST is to investigate the coupled thermo-mechanical, thermo-chemical and thermohydrological responses of the Topopah Spring tuff in Yucca Mountain.

This paper describes electrical resistance tomography (ERT) surveys made during the DST in order to map the changes in moisture content caused by the heating of the rock mass. Of particular interest, is the formation and movement of condensate within the fractured rock mass.

The DST is located off the Observation Drift about $40 \mathrm{~m}$ from the Main Tunnel of the ESF and about $2.8 \mathrm{~km}$ from the portal of the Tunnel. As shown in Figures 1 and 2, twelve boreholes were drilled form the HD and the AOD and electrodes emplaced. A total of 200 electrodes distributed among the 12 holes are used to conduct ERT surveys around the HD. 


\section{Electrical Resistance Tomography:}

Electrical resistance tomography (ERT) is a geophysical imaging technique which can be used to map subsurface resistivity. This technology has been successfully used to monitor a variety of subsurface processes such as steam injection, air sparging, and contaminant spills (e.g., LaBrecque, et al., 1996; Daily et al., 1998; Ramirez et al., 1996. Here we discuss the use of ERT to monitor electrical resistivity changes which develop during heater tests. This approach has been used successfully in other YMP heater tests such as the Single Heater Test and the Large Block Test.

Rock mass heating creates temperature and liquid saturation changes which result in electrical resistivity changes that are readily measured. The ERT measurements consist of a series of voltage and current measurements from buried electrodes using an automated data collection system. The data are then processed to produce electrical resistivity tomographs using state of the art data inversion algorithms. We use these measurements to calculate tomographs that show the spatial distribution of the subsurface resistivities.

To calculate the changes in the rock's electrical resistivity we compared a data set obtained after heating started, and a corresponding data set obtained prior to heating. One may consider subtracting, pixel by pixel images from two different conditions. However, this approach could not be used because the resistivity structure was three-dimensional, i.e., several boreholes containing metallic instruments, were located near the plane of interest (see Figure 1). These metallic instruments caused large conductive anomalies and made the resistivity structure three dimensional (3D). The finite element forward solver is 2 dimensional and therefore, cannot generate a model that will fit the data so the code chooses a solution with a poor fit. Our experience is that these effects can be reduced by inverting the quantity:

$$
\frac{R_{a}}{R_{b}} \times R_{h}
$$

where $R_{a}$ is the measured transfer resistance after heating started, $R_{b}$ is the transfer resistance before heating and $R_{h}$ is the calculated transfer resistance for a model of uniform resistivity. This approach tends to reduce the effects of anomalies which do not change with time because they are contained in both terms $\mathrm{R}_{\mathrm{a}}$ and $\mathrm{Rb}$. 


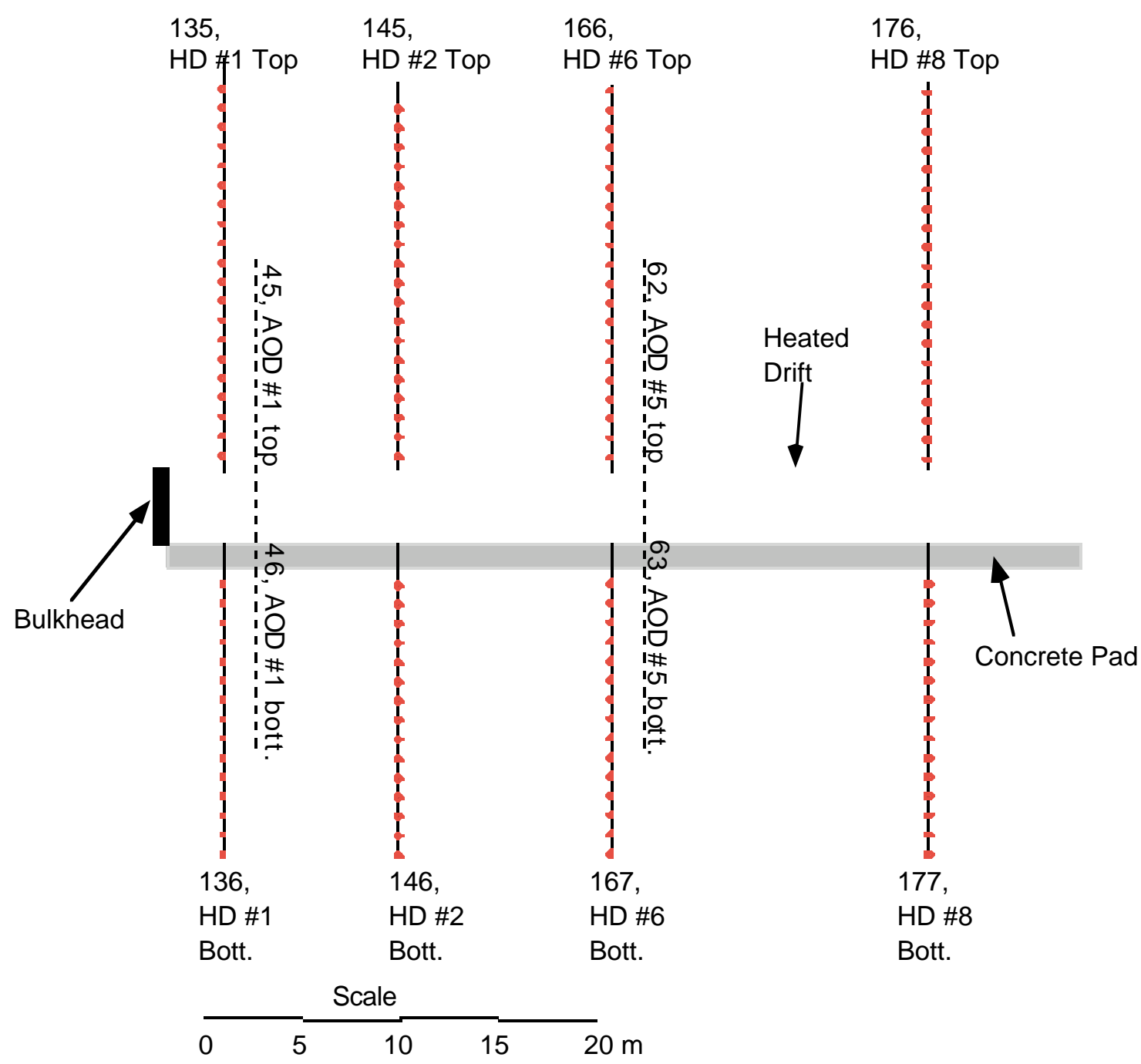

Figure 1. Cross section parallel to the HD showing the location of ERT boreholes. Boreholes drilled from the from the HD are shown as solid lines extending above and below the HD. The location of the electrodes within each borehole is shown by the small circles. The location of boreholes drilled from the AOD is shown by dashed lines. The electrode spacing for the boreholes drilled from the HD is 1 meter.

Here we describe briefly some of the important features of the two dimensional (2D) algorithm. For additional details, the reader is referred to Morelli and LaBrecque (1996). The algorithm solves both the forward and inverse problems. The forward problem is solved using a finite element technique in 2D. The inverse problem implements a regularized solution which minimizes an objective function. The objective of the inverse routine is to minimize the misfit between the forward modeling data and the field data, and a stabilizing functional of the parameters. The stabilizing functional is the solution's roughness. This means that the inverse procedure tries to find the smoothest resistivity model which fits the field data to a prescribed tolerance. Resistivity values assigned in this way to the finite element mesh constitute the ERT image. 

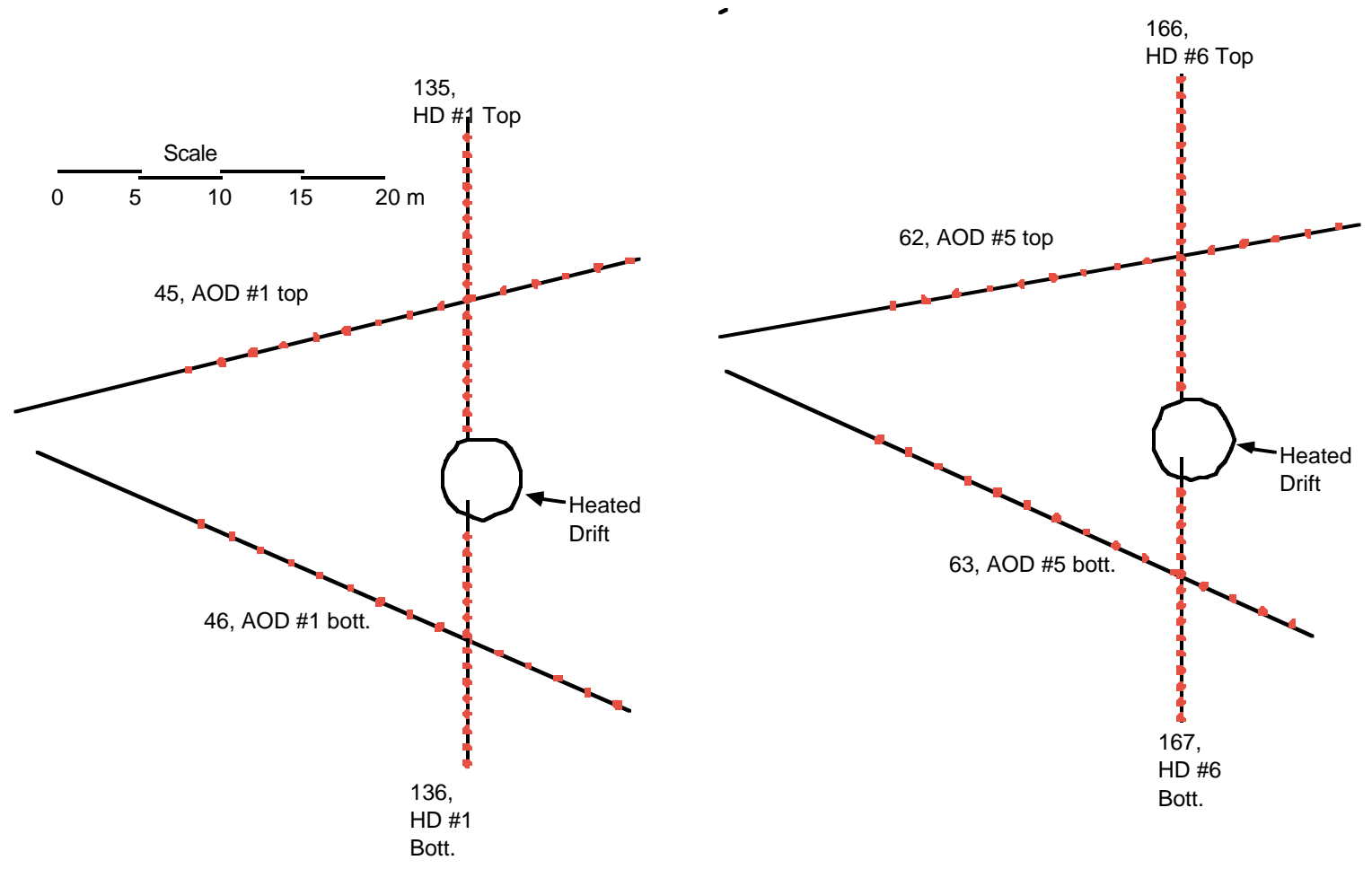

Figure 2. Two cross sections orthogonal to the HD showing the location of ERT boreholes drilled from the AOD and selected boreholes drilled from the HD. The location of the electrodes within each borehole is shown by the small circles. The electrode spacing is 1 meter for the boreholes drilled from the HD and $2 \mathrm{~m}$ for the boreholes drilled from the AOD.

Although the mesh is of a large region around the electrode arrays, only the region inside the ERT electrode array is shown in the results because the region outside the array is poorly constrained by the data.

\section{Description of ERT surveys:}

Along the HD, ERT survey data were collected between adjacent pairs of boreholes. For example, surveys collected below the Heated Drift are collected between boreholes $136-146,146-167$, and 167-177. A similar approach is used for surveys collected above the HD. These surveys provide information along two vertical planes (one above and one below the HD) which run parallel to the HD.

The surveys performed from boreholes drilled from the AOD provide information along two vertical planes which run orthogonal to the HD. These surveys are performed by combining electrodes in AOD boreholes with electrodes in HD boreholes. We take advantage of the fact that HD boreholes 135 and 136 are close to AOD boreholes 45 and 46; similar comments apply to both AOD boreholes 62 and 63, and HD boreholes 166 and 167. For these surveys, the shallowest (closest to the AOD) 10 electrodes in AOD boreholes 45 and 46 
were used in combination with the shallowest 5 electrodes (to the HD) in HD boreholes 135 and 136 . This approach provides better sensitivity and resolution of the rockmass on the left flank (looking towards the end of the HD) of the HD relative to the sensitivity and resolution which would result if only electrodes in the AOD boreholes were used.

\section{Changes in Electrical Resistivity:}

Tomographs of resistivity change corresponding to the time period between $12 / 17 / 97$ and $3 / 18 / 98$ are shown in Figures 3,4 , and 5 . We will first discuss the tomographs collected along a cross-section parallel to the HD (Figure 3). The upper left part of Figure 3 shows the changes in resistivity calculated after 14 days of heating. Note that most of the tomographs are yellow-green in color, thereby indicating resistivity ratios near 1.0 (no change condition). After 42 days of heating most of the rock shows a ratio of 1.0 , but the rock near the crown and invert of the HD is beginning to show resistivity decreases (ratios smaller than 1.0). These decreases become stronger as heating time increases (lower left and lower right portions of Figure 3). The tomographs also indicate that the resistivity changes above the $\mathrm{HD}$ are stronger than those below the $\mathrm{HD}$. We believe that these resistivity changes are due to increases in temperature that have developed close to the walls of the HD.

Some of the rock between boreholes 6 and 8 above the HD shows slight resistivity increases close to borehole 8 for the 1/14/98 and 2/26/98 results. These slight resistivity increases later disappear from the 3/18/98 results. The reason(s) for this increase are unknown.

Now our discussion focuses on resistivity change tomographs sampling the rockmass along vertical planes at right angles to the HD. Figure 4 shows tomograph planes which are coincident with the AOD 5 boreholes and intersect the HD near its middle. The 12/17/97 results are not shown because they are considered unreliable; we suspect that errors were made in connecting the measurement system to the electrodes. The convergence behavior for this inversion was different from the behavior of other planes, and visual inspection of the raw data indicated that many of the readings were significantly different from readings collected in the preceding and succeeding surveys.

The remaining images in Figure 4 show resistivity decreases near the location of the wing heaters. Although the mesh consists of a large region around the electrode arrays, only the region inside the ERT electrode array is shown in the figure because the region outside the array is poorly constrained by the data. The region inside the HD is also masked because the technique does not measure rock properties in the excavated region. The resistivity decreases within the rock grow stronger with heating time. Also, the zone of resistivity changes extends farther into the rock above the HD than below the HD.

It is our interpretation that the observed resistivity changes are caused primarily by decreases in the resistivity of the pore water as temperature increases, and not by drying of the rock. Drying of the rock would make the resistivity ratio go up. Any drying that may be occurring in the rock is having the opposite effect of 
making the resistivity ratio go up. Figure 4 makes it clear that resistivity decreases are the norm, and thus that the temperature effect on pore water is dominating the resistivity changes observed during this time period.

Figure 5 shows one other vertical plane at right angles to the HD; this one is located close to the bulkhead that seals off the HD. The 12/17/97 results are not shown because they are considered unreliable as discussed above. There are similarities and differences between the Figure 4 and 5 results. Both show resistivity decreases near the HD which extend deeper into the rock above the crown of the HD than below its invert. The decreases also become stronger as heating time advances. Significant differences between the Figure 4 and 5 results are observed in the vicinity of the wing heaters. The Figure 5 tomographs show much weaker decreases in resistivity in this area. Assuming that the primary factors affecting electrical resistivity are temperature and saturation, the weaker decreases by the wing heaters suggest that either: 1) the rock is cooler close to the bulkhead, or that 2) its saturation is decreasing at a faster rate than near the middle of the HD, or that 3) other effects are masking the true rock response. Temperature data in this area suggests that hypothesis 1 is probably not true.

Another possibility, is that the large metallic structure making up the bulkhead is a very good conductor thereby focusing the electrical current away from the rock mass (hypothesis 3). This condition would tend to create an area of low ERT sensitivity near the bulkhead. This is consistent with a previous report (milestone \#SPY 195M4). In that report, the pre-heating baseline tomograph near the bulkhead indicated very low resistivity close to the HD near the location of the wing heaters. The root cause of this low-resistivity region may be the proximity of this part of the rock to the bulkhead metal structure. 


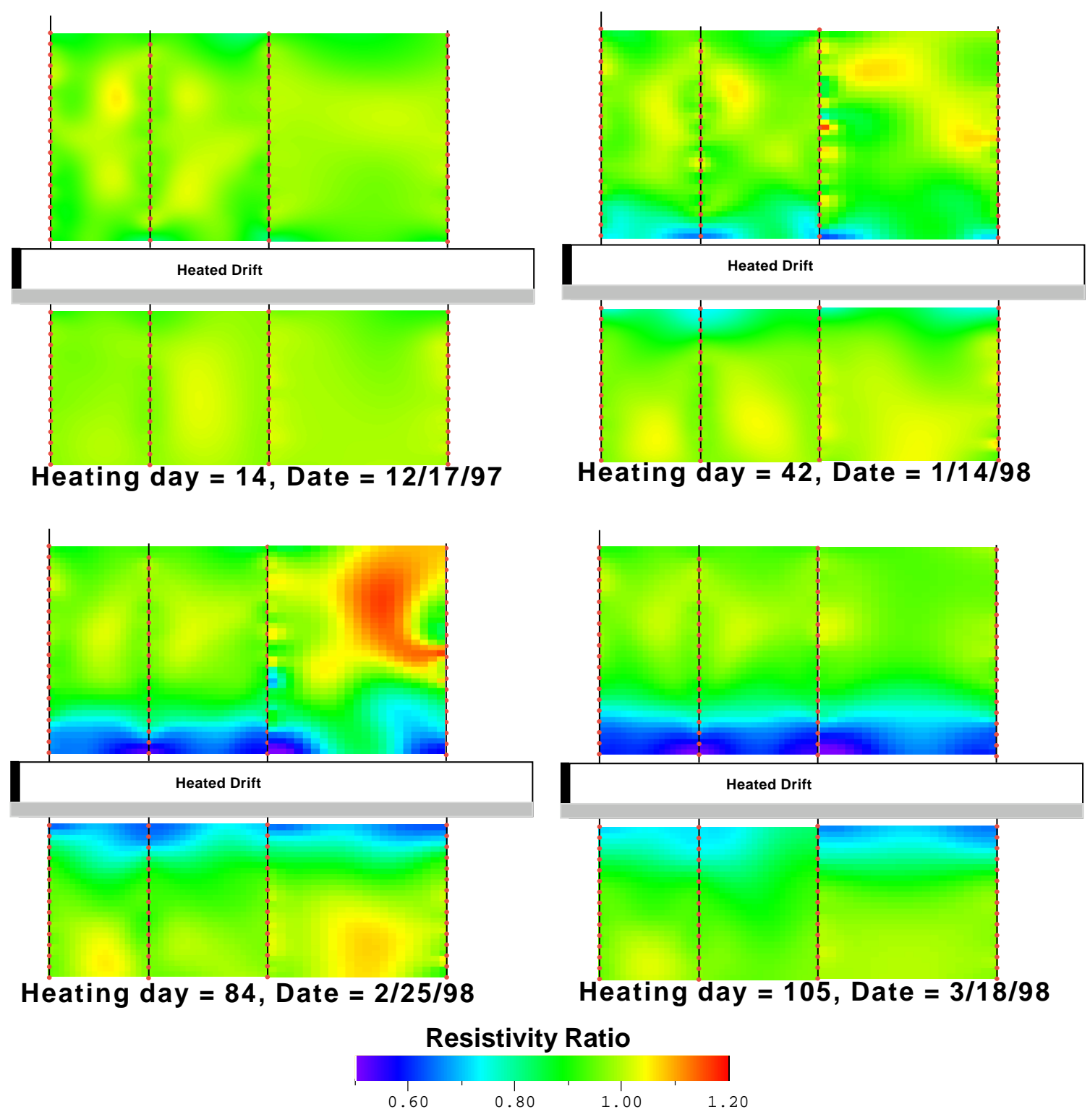

Figure 3. Shows tomographs of electrical resistivity ratio along a cross-section parallel to the HD; tomographs located above the crown and below the invert of the HD are shown. The tomographs show changes relative to the pre-heating $(11 / 18 / 97)$ electrical resistivity distribution. A resistivity ratio equal to 1.0 indicates no change; values less than 1.0 indicate that the resistivity is decreasing relative to the baseline. 
Figure 4. Shows tomographs of electrical resistivity ratio along a cross-section which is orthogonal to the HD, and near its middle, and coincident with the AOD 5 boreholes shown in Figures 1 and 2. The tomographs show changes relative to the pre-heating $(11 / 18 / 97)$ electrical resistivity distribution. A resistivity ratio equal to 1.0 indicates no change; values less than 1.0 indicate that the resistivity is decreasing relative to the baseline.

Figure 5. Shows tomographs of electrical resistivity ratio along a cross-section which is orthogonal to the HD and near the bulkhead. The tomographs show changes relative to the pre-heating $(11 / 18 / 97)$ electrical resistivity distribution. A resistivity ratio equal to 1.0 indicates no change; values less than 1.0 indicate that the resistivity is decreasing relative to the baseline. 

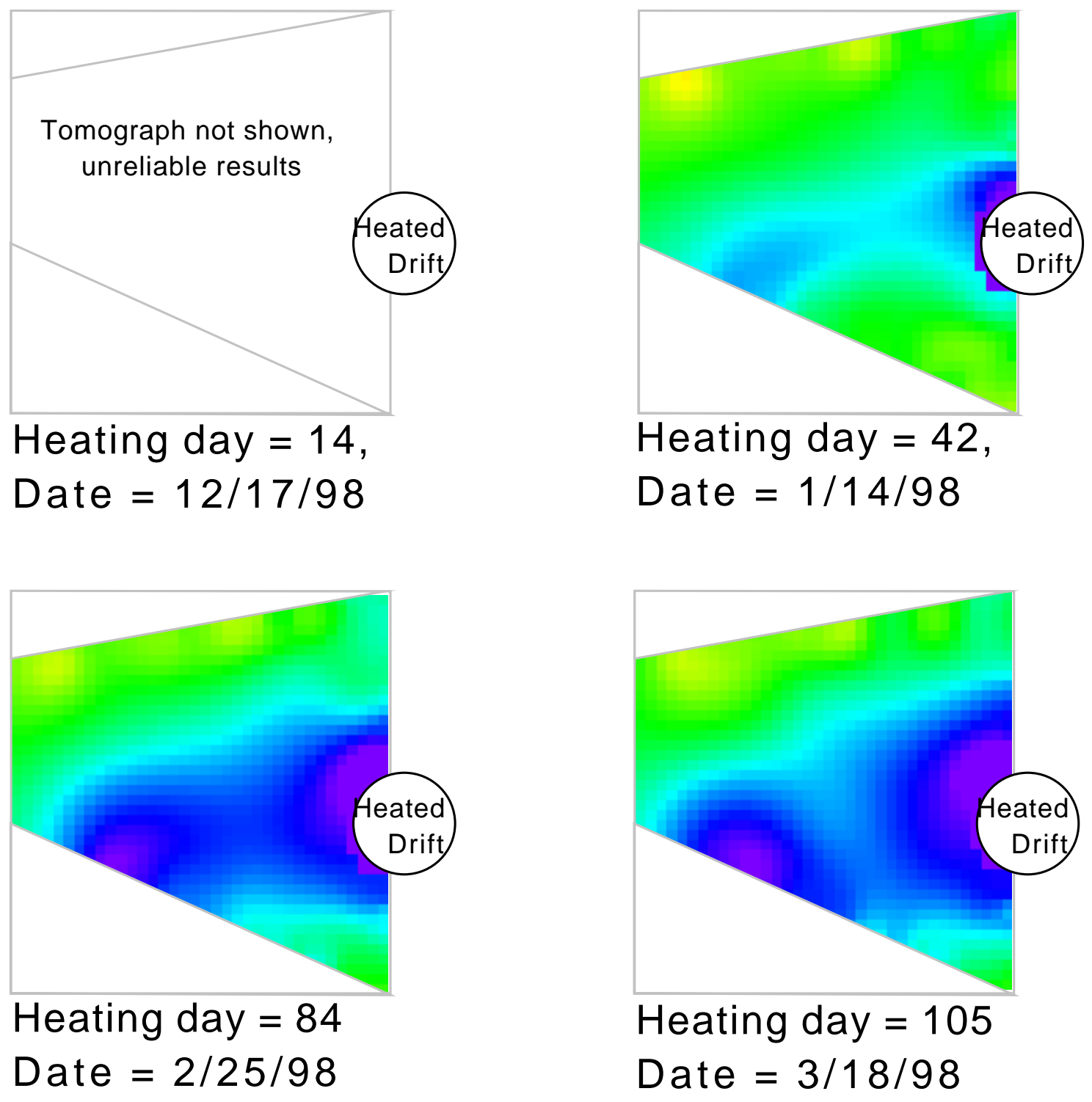

Resistivity Ratio

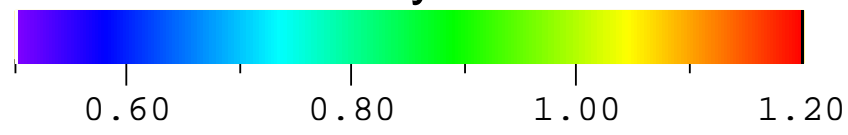



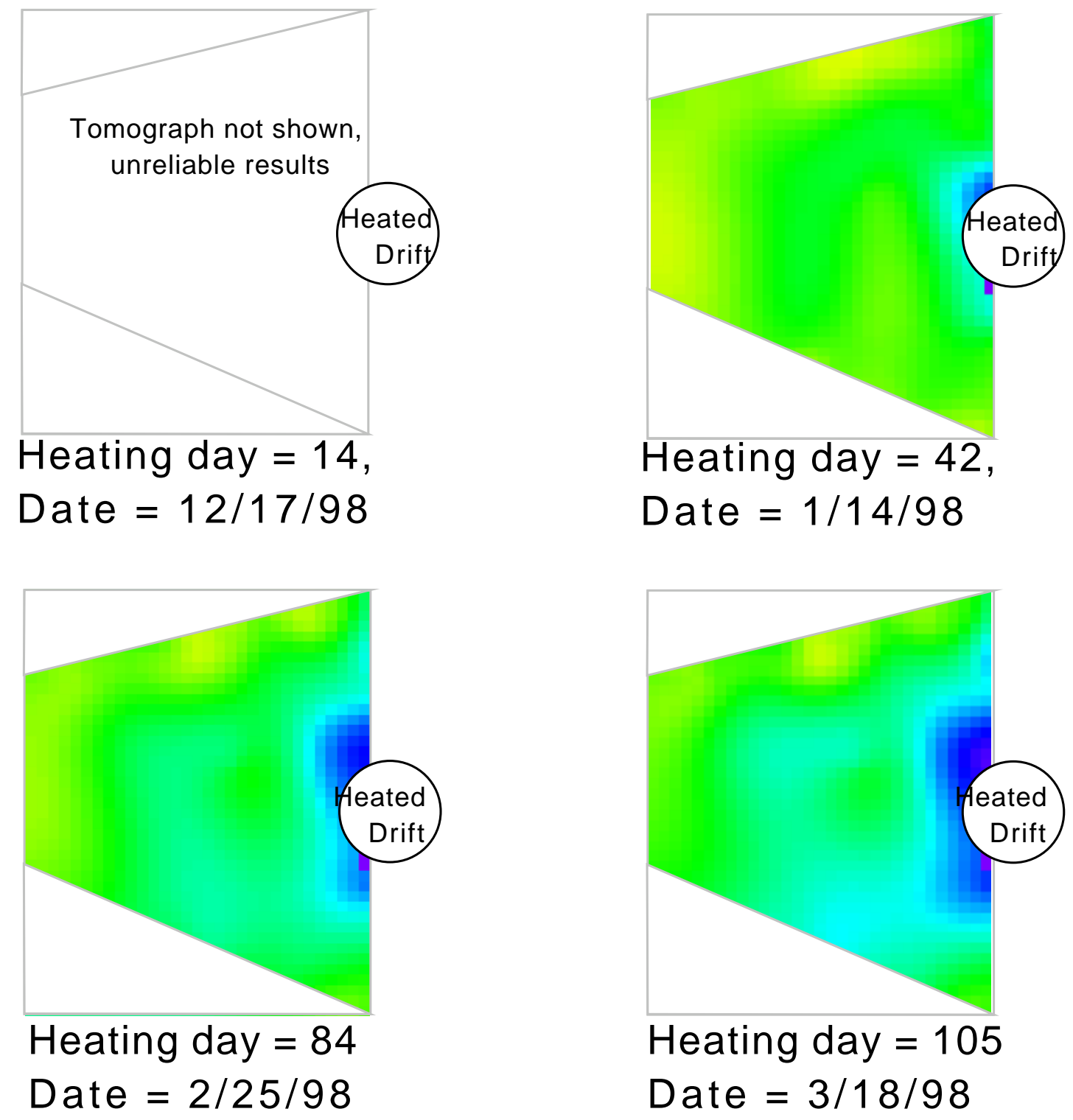

\section{Resistivity Ratio}

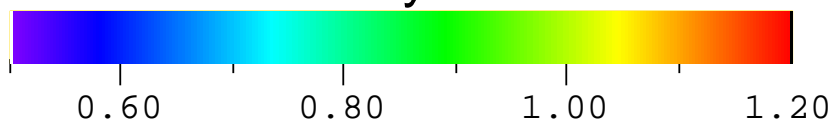




\section{Estimates of Saturation Change:}

The resistivity changes in Figures 3,4 and 5 are influenced by changes in moisture content, temperature, ionic strength of the water and mineralogy. In order to estimate saturation, we assume that the dominant factors affecting resistivity changes are temperature and saturation. That is, an increase in temperature or moisture causes a resistivity decrease. Near the heaters, there may be regions where the increasing temperature reduces the resistivity, while rock drying, changes the resistivity in the opposite sense (increases the resistivity). Our goal in this section is to use the images of resistivity change near the HD, along with the measured temperature field and what is known of initial conditions in the rockmass to estimate moisture change during heating. A detailed description of our approach can be found on a previous milestone report pertaining to the Single Heater Test ( milestone \#SP9215M4). Here we summarize some of the highlights of this approach.

In order to estimate moisture content changes, we need to account for both effects of temperature, measured at many points by temperature sensors, and resistivity changes, measured by ERT. We used the available temperature data to construct temperature maps along the ERT planes. It is necessary to have a reliable temperature measurement for each area (each tomograph pixel) were we wish to calculate the saturation change. Interpolation of temperature measurements made at discrete points was necessary to develop the temperate images used for this approach. Note that the temperature estimates were generated following a NON QUALIFIED process; therefore, the saturation estimates are NON QUALIFIED. Also, the saturations estimates are considered approximate as indicated later in this write-up.

A petrophysical model known as the Waxman Smits model is used to produce the saturation estimates. As indicated in milestone \#SP9215M4, when the Waxman Smith model is used in ratio form, it simplifies to two possible models. Model 1 indicates the relationship between saturation and resistivity for the case were the primary conduction pathway is the through the water in the open pore space. Model 2 indicates the relationship between saturation and resistivity for the case the primary conduction pathway is surface conductance within the electrical double layer which exists at the interface between the silicate matrix and pore water. Model 2 exhibits a higher sensitivity to saturation change than Model 1. These two models bracket the range of possible relationships between saturation and resistivity. Since rock conditions are changing in space and time during heating, we have chosen to estimate the changes in saturation by using both model 1 and 2. This approach should provide bounds to the domain of possible saturations that may be present. Neither of these two models accounts for changes in water resistivity cause by rock/water chemical interactions. If chemical reactions cause large changes in the concentration or types of ions in the water, the estimated saturation changes will be in error. 
Figure 6 shows estimates of saturation change according to model 1, along a cross-section which is parallel to and near the middle of the HD. The estimates show changes relative to the pre-heating (11/18/97) saturation distribution. A saturation ratio equal to 1.0 indicates no change; values less than 1.0 indicate that the saturation is decreasing relative to the baseline.

Figure 7 shows estimates of saturation change according to model 2, along a cross-section which is parallel to and near the middle of the HD. The estimates show changes relative to the pre-heating (11/18/97) saturation distribution. A saturation ratio equal to 1.0 indicates no change; values less than 1.0 indicate that the saturation is decreasing relative to the baseline.

Figures 6 and 7 show the saturation change estimates along the axis of the HD using models 1 and 2 . Note that both model estimates indicate that most of the rock has a saturation ratio of about 1.0 (no change relative to the baseline). The available estimates suggest that some drying is occurring close to the HD and that the drying zone is growing very slowly with time. Figures 6 and 7 suggest that most of the drying is occurring above the HD between boreholes 6 and 8 . As indicated by milestone \#SP9215M4, our educated guess is that Model 2 may be closer to the real saturation changes than model 1 . Thus, we

Figure 8 shows estimates of saturation change according to model 1, along a cross-section which is orthogonal to and near the middle of the HD, and coincident with the AOD 5 boreholes. The estimates show changes relative to the pre-heating (11/18/97) saturation distribution. A saturation ratio equal to 1.0 indicates no change; values less than 1.0 indicate that the saturation is decreasing relative to the baseline.

Figure 9 shows estimates of saturation change according to model 2, along a cross-section which is orthogonal to and near the middle of the HD, and coincident with the AOD 5 . The estimates show changes relative to the preheating (11/18/97) saturation distribution. A saturation ratio equal to 1.0 indicates no change; values less than 1.0 indicate that the saturation is decreasing relative to the baseline.

use the estimates shown in Figure 7 to suggest that the rock showing the maximum amount of drying has lost about $1 / 2$ half of its water by 2/25/98. 

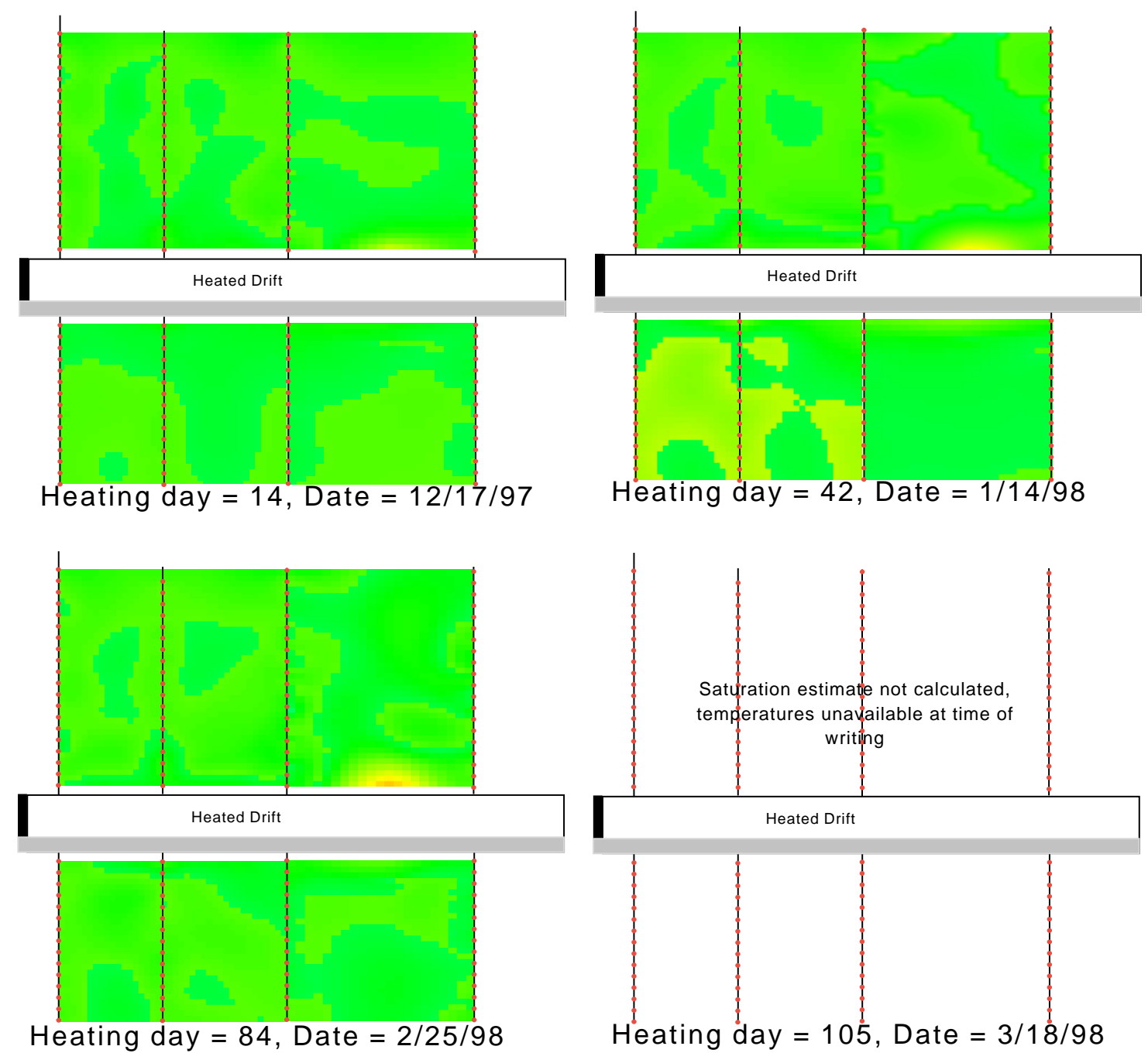

Saturation Ratio

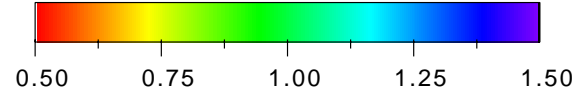




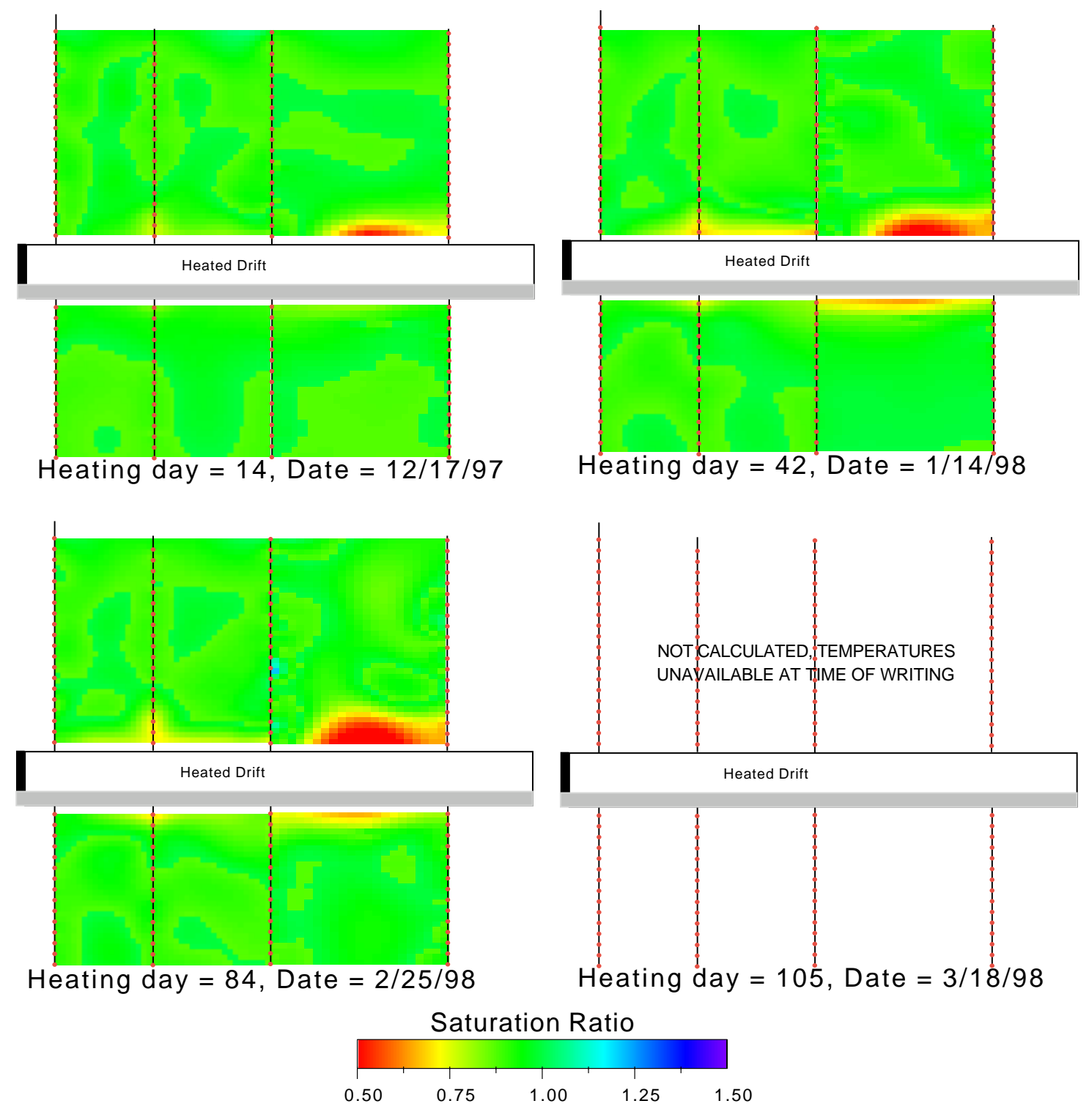



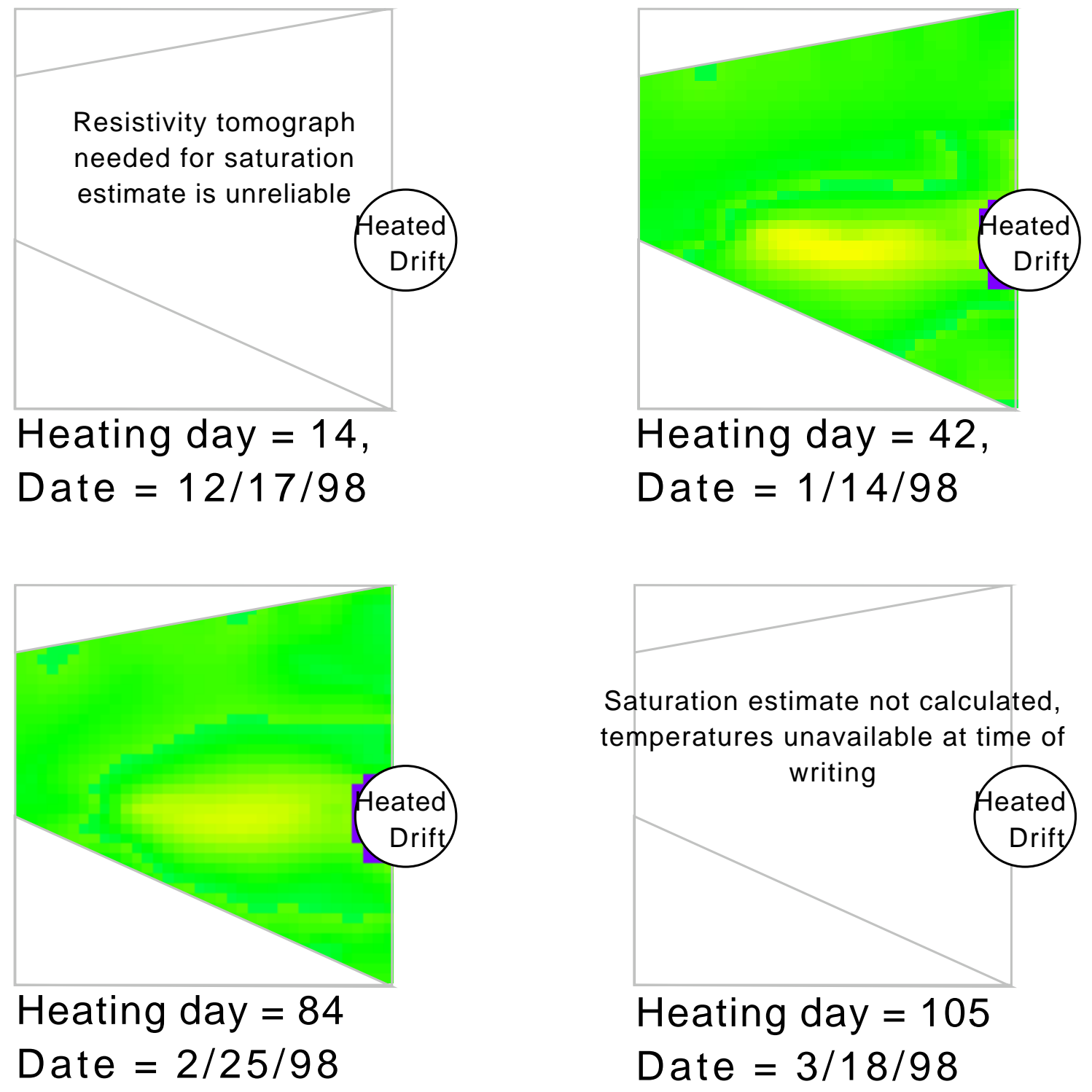

Saturation Ratio

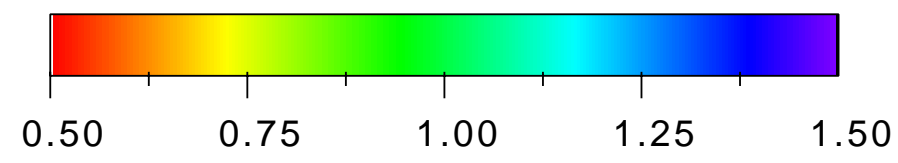



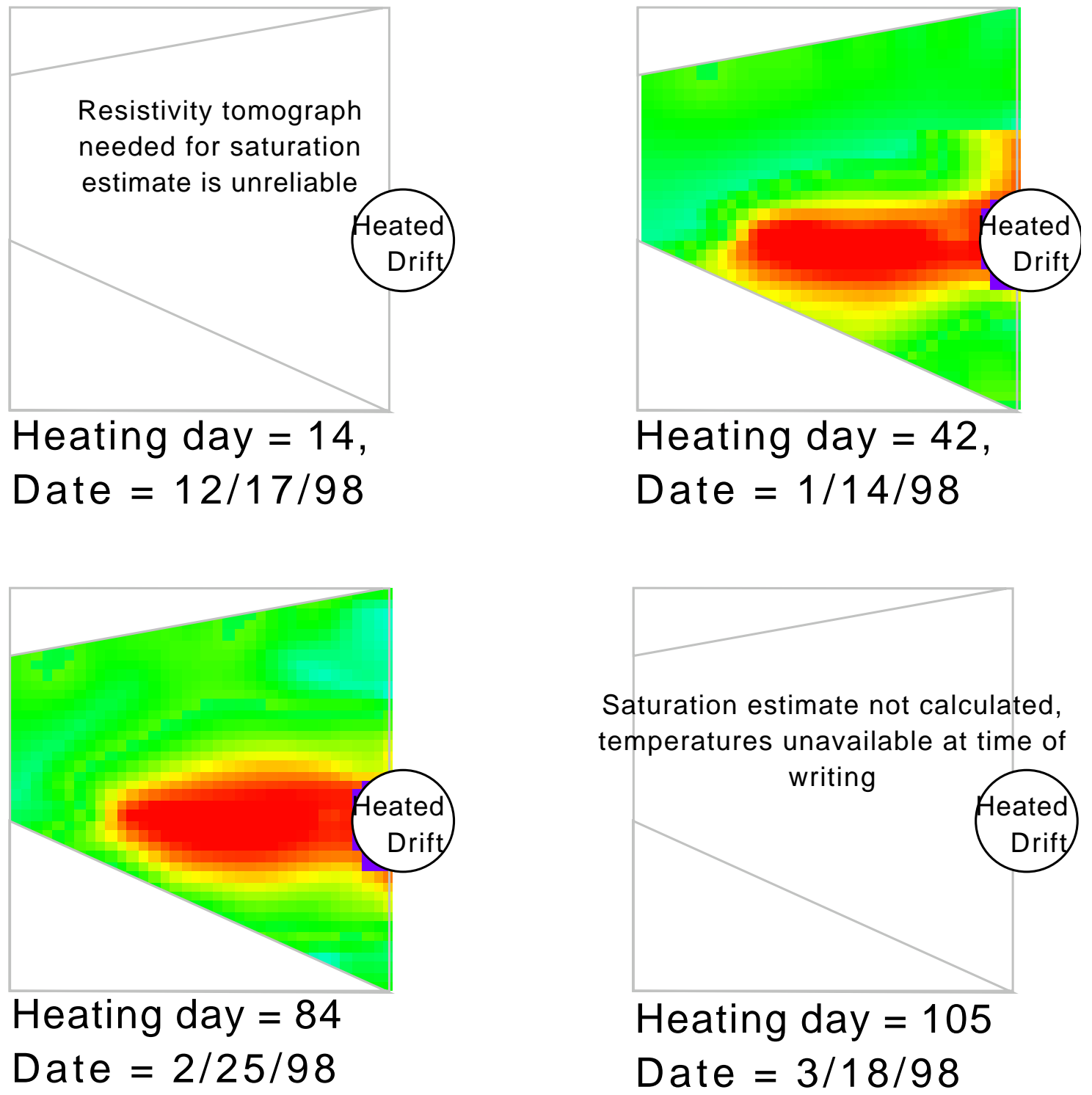

Heating day $=84$

Date $=2 / 25 / 98$

Date $=3 / 18 / 98$

Saturation Ratio

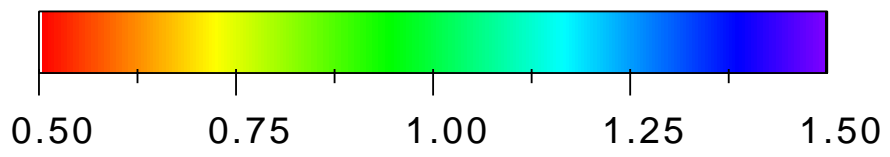


Figures 8 and 9 show the saturation change estimates perpendicular to the axis of the HD close to the middle of the HD, using models 1 and 2. The figures show a horizontal zone of drying developing near the wing heaters. A comparison of the 1/14/98 and 2/25/98 results suggest that the drying zone may be growing slowly with time. The estimated saturation ratios near the wing heaters are about 0.5 , i.e., the rock showing the maximum amount of drying has lost about $1 / 2$ half of its water by $2 / 25 / 98$.

Figures 10 and 11 show the saturation change estimates for a plane perpendicular to the axis of the HD, close to the bulkhead, and coincident with the AOD 1 boreholes. When compared to Figures 8 and 9, Figures 10 and 11 show a stronger zone of drying which extends beyond the zone where the wing heaters are located. As shown by the resistivity ratios in Figure 5, the resistivity changes observed around the wing heaters near the bulkhead are weaker than those observed closer to the center of the HD. The petrophysical model used to provide saturation estimates, interprets the weaker changes as stronger drying near the bulkhead. If the reason for the weaker resistivity changes is a "blind zone" or low sensitivity zone caused by the metal in the bulkhead, then these high drying estimates are simply due to low sensitivity to the true changes actually occurring in the rock.

On the other hand, there are reasonable physical arguments which might suggest that the saturation estimates near the bulkhead are valid. There are two reasons for expecting this ERT plane to behave different from the AOD 5 plane.

First, this plane is close to the end of the HD and to the associated access drifts. This proximity means that there may be enhanced drying of this part of the rockmass since it is better connected by natural and induced fractures to the ventilation system. This argument supports the fact that the moisture calculations indicate a stronger drying in this image plane.

Furthermore, water was produced by one of the boreholes drilled near the bulkhead. This anecdotal evidence suggests that there may have a small, water saturated rubble zone. A small volume of pendular water in this otherwise highly resistive rockmass would image as a strong conductive anomaly, even after being drained of the bulk water at drilling. Coincidentally, a strong conductive anomaly was present in the baseline images of AOD 1 (not shown here), adjacent to the wing heaters. This type of anomaly might explain the unusual resistivity patterns which formed in this plane and why the anomalous moisture changes calculate from them do not look like the results from AOD 5.

All of the saturation estimates presented are considered to be approximations. The accuracy of the saturation estimates in Figure 4 may be limited by one or more of the following factors. 1) The accuracy of the temperature maps in the 
vertical direction is limited by the sparse vertical coverage of the temperature sensors. Errors in the interpolated/extrapolated temperature maps will result in erroneous saturation estimates. 2) The effects of rock/water interactions on electrical resistivity are not accounted for by the Waxman Smits model. This means that if significant changes develop in the number or types of ions in solution may cause resistivity changes that the model would treat as saturation changes. Data from DST water samples may be helpful in understanding this effect. 3) Laboratory measurements of the electrical resistivity of welded tuff (Roberts and Lin, 1997) indicate that the Waxman Smits model underpredicts resistivity for saturations below $20 \%$. No saturation estimates below $20 \%$ are present in Figures 6 to 11; this might become a limitation as drying near the heaters progresses. 4) The resistivity ratios were calculated using a 2D algorithm whereas natural heterogeneities such as fractures are likely 3D. Changes in resistivity occurring along fractures (or any other regions which don't meet the 2D assumptions of the inversion algorithm) may be distorted. 5) Several metallic objects are located near the planes of interest (bulkhead, heater canisters, steel mesh around the HD periphery. These metallic objects cause large conductive anomalies which tend to reduce sensitivity to resistivity changes occurring in the rock thereby resulting in resistivity change tomographs which show smaller change than those present in the rock. 6) The ratio technique used to process the ERT data is an approximate technique which is best suited for situations of low resistivity contrast. The presence of metallic instruments created a high contrast anomaly which may adversely impact the ERT ratio tomographs. 

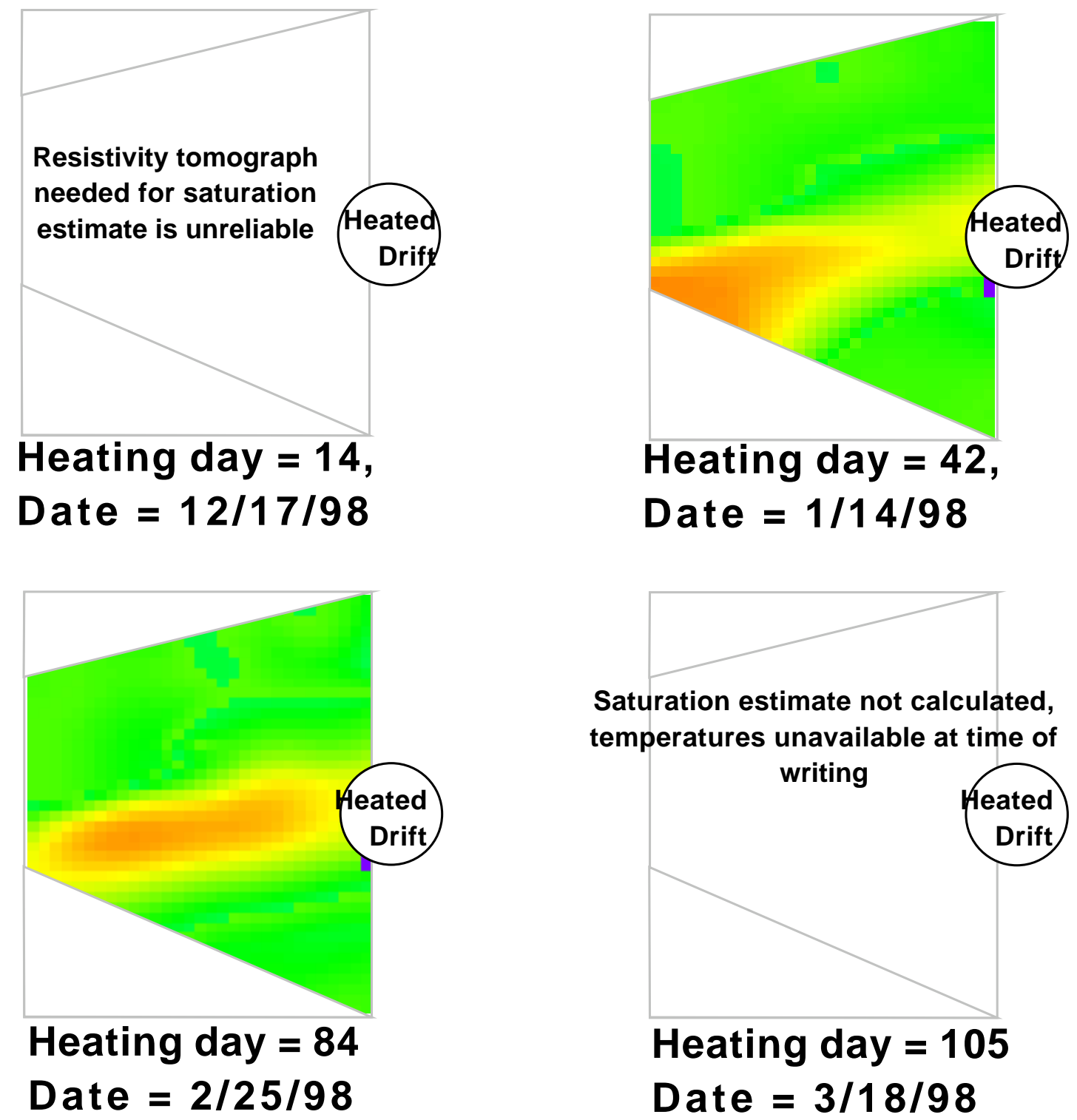

Saturation estimate not calculated, temperatures unavailable at time of

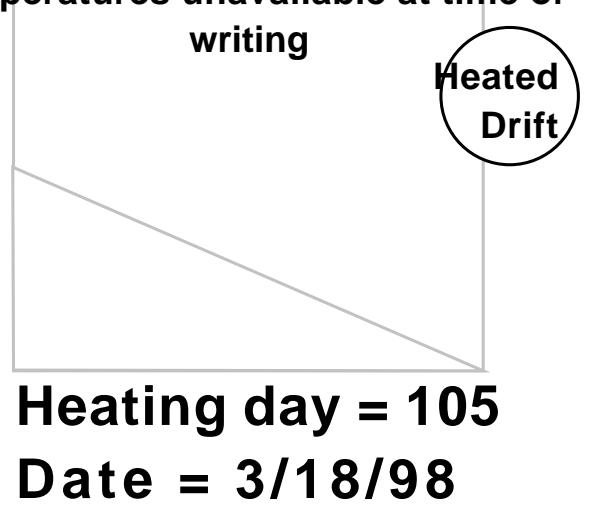

Saturation Ratio

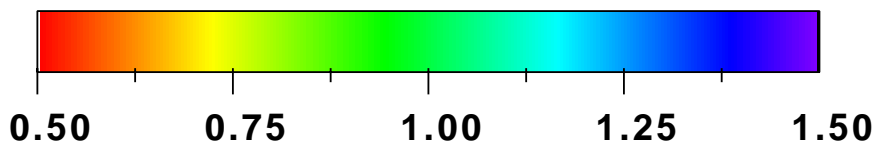



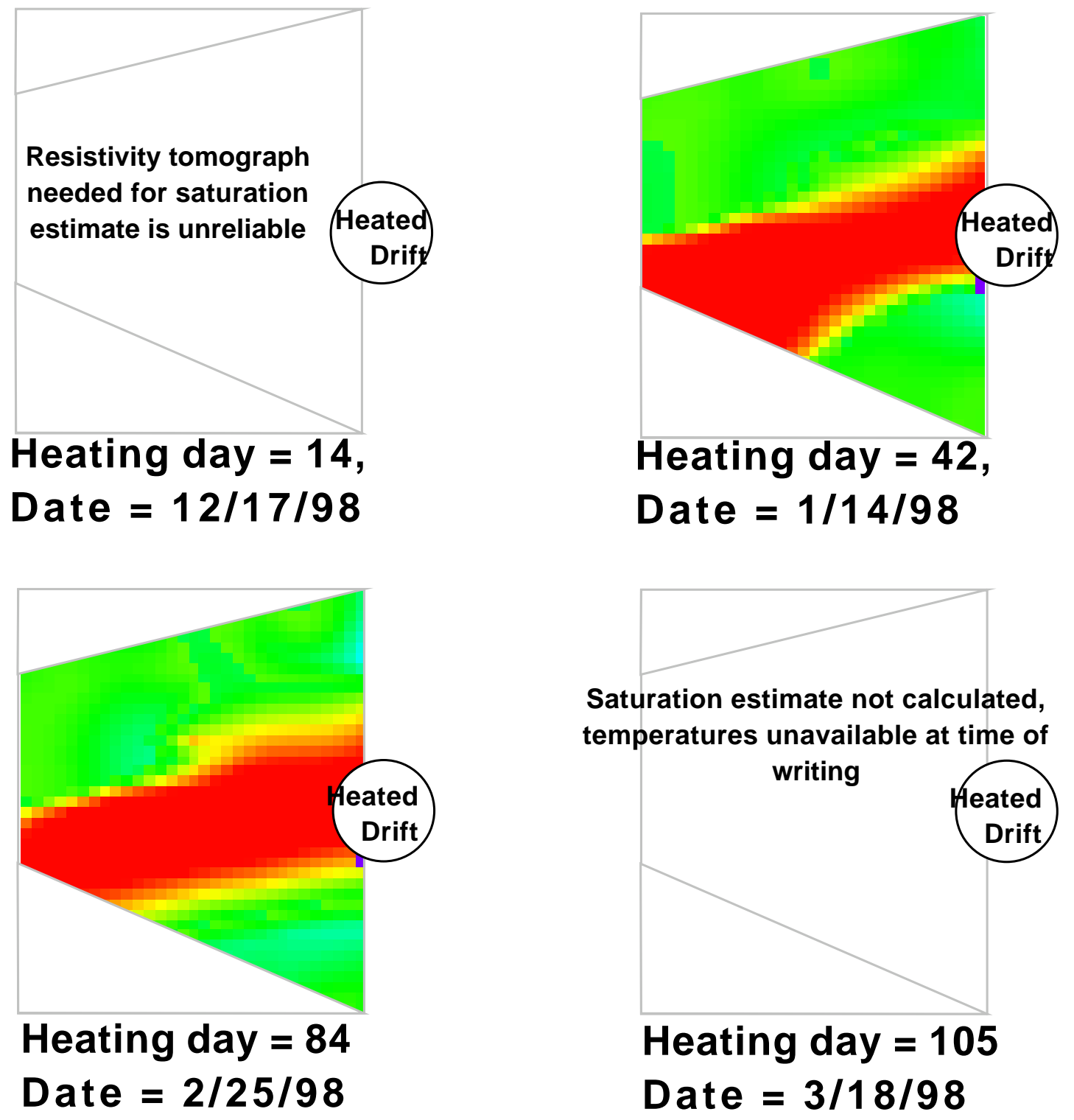

Saturation Ratio

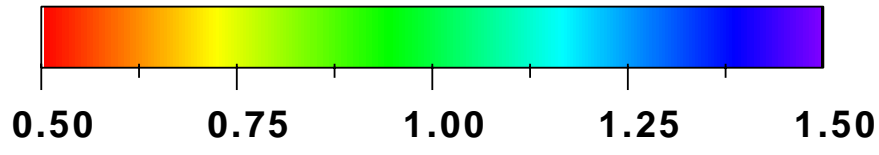




\section{Summary and Conclusions:}

ERT surveys have been conducted around the HD before and after heating started. The surveys are made along a series of vertical planes, some of which are parallel to the HD, and others which are orthogonal the HD. During this quarter, three data sets were collected and processed after heating started. The filed data was used to produce tomographs of electrical resistivity change. These tomographs primarily show electrical resistivity decreases during the course of heating. The electrical resistivity changes have been used in combination with temperature maps of the region and a petrophysical model to calculate maps of saturation change around the HD. The saturation estimates suggest that a region of significant drying region has developed near the location of the wing heaters. A less significant drying region appears to exist above the crown of the HD.

\section{Acknowledgments:}

This work is supported by Yucca Mountain Site Characterization Project, LLNL.

We acknowledge the contributions of colleagues Jeff Wagoner, who provided the interpolated temperature images used in the saturation calculations and, $\mathrm{H}$. Michael Buettner, which assisted in data collection.

\section{References:}

Daily, W. D., A. Ramirez and R. Johnson, 1998, Electrical impedance tomography of a perchloroethelyne release, J. Envir. and Eng. Geophysics, vol. 2, No. 3, pp. 189-201.

LaBrecque, D. J., A. Ramirez, W. Daily, A. Binley and S. Schima, 1996, ERT Monitoring of Enviromental Remediation Processes, Meas. Sci. Technol., vol. 7, .pp. 375-383.

Morelli, G., and D. LaBrecque, 1996, Robust Scheme for ERT Inverse Modeling, Proc. Symposium on the Application of Geophysiscs to Engineering and Environmental Problems, Keystone, April 28 - May 2, 1996.

Ramirez, A., W. Daily, A. Binley, D. LaBrecque, and D. Roelant, 1997, Detection of Leaks in Underground Storage Tanks Using Electrical Resistance Methods, Journal of Enviromental. and Eng. Geophysics., vol. 1, no. 1, pp 189-203.

Roberts, J. and W. Lin, 1997, Electrical properties of partially saturated Topopah Spring tuff: Water distribution as a function of saturation, Water Resources Research, 33,577-587. 


\section{YMP-023-R4 YUCCA MOUNTAIN SITE CHARACTERIZATION PROJECT}

05/06/96

\section{TECHNICAL DATA INFORMATION}

Page 1 of 2

(Check one): $\quad \mathrm{x}$ ACQUIRED DATA (complete Parts I and II)

Data Tracking Number (DTN):

LL 980406404244.057

$\square$ DEVELOPED DATA (complete Parts I, II and III)

Data Tracking Number (DTN):

\section{PART I Identification of Data}

Title/Description of Data: FIRST QUARTER FY98 RESULTS OF ERT MEASUREMENTS IN THE DRIFT SCALE TEST.

Principal Investigator (PI): $\frac{\text { RAMIREZ, A * }}{\text { Last }}$

PI Organization: LAWRENCE LIVERMORE NATTONAL LAABORATORY

Are Data Qualified?: $\mathrm{X}$ Yes $\square$ No $\quad$ Governing Plan:

SCPB Activity Number(s): $\frac{8.3 .4 .2 .4 .4 .2}{14.2}$

WBS Number(s): 1.2 .3 .14 .2

\section{PART II Data Acquisition/Development Information}

Method: DONE UNDER LLNL STUDY PLAN 8.3.4.2.4.4. ELECTRICAL RESISTANCE TOMOGRAPHY (ERT) IS A GEOPHYSICAL IMAGING TECHNIQUE THAT CAN BE USED TO MAP SUBSURFACE RESISTIVITY. ROCK MASS HEATING CREATES

TEMPERATURE AND LIQUID SATURATION CHANGES THAT RESULT IN ELECTRICAL RESISTIVITY CHANGES THAT ARE READILY MEASURED. THE ERT MEASUREMENTS CONSIST OF A SERIES OF VOLTAGE AND CURRENT MEASUREMENTS FROM

Location(S): MMP-ESF-DST

Period(s): $\frac{1 / 1 / 97 \text { to } 3 / 1 / 97}{\text { From: MMODMY }}$ To: MMNDNY

Sample ID Number(s):

PART III Source Data DTN(s)

\section{Comments}

LLNL MILESTONE SP2640M4

checked by: $7 n \cdot$ Fanne Yalmen Signature

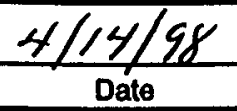

YAP-SIII.3Q.1 


\section{YMP-023-R4 YUCCA MOUNTAIN SITE CHARACTERIZATION PROJECT}

08/31/95 TECHNICAL DATA INFORMATION CONTINUATION SHEET

* Page 2 of 2

Method (continued)

BURIED ELECTRODES USING AN AUTOMATED DATA COLLECTION SYSTEM. THE DATA IS THEN PROCESSED TO PRODUCE ELECTRICAL RESISTIVITY TOMOGRAPHS USING STATE-OF-THE-ART DATA INVERSION ALGORITHMS. THESE TOMOGRAPHS SHOW THE SPATIAL DISTRIBUTION OF THE SUBSURFACE RESISTIVITIES. 


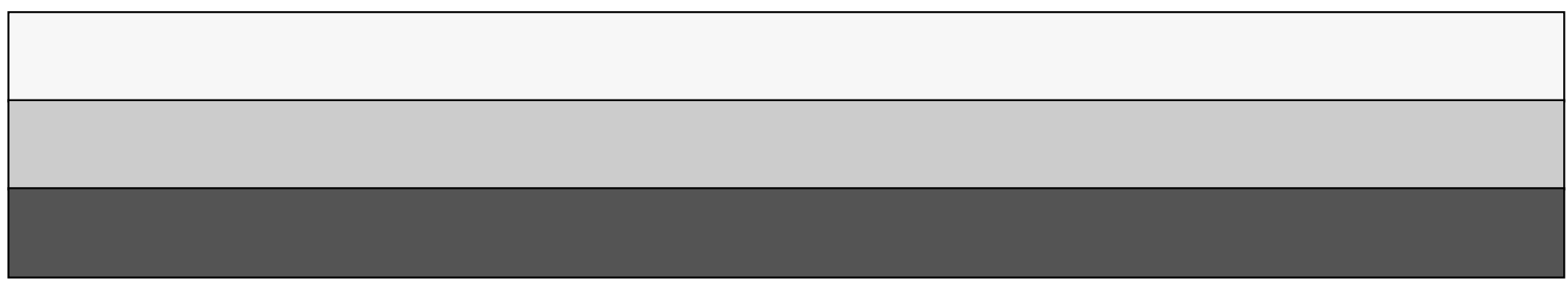

